\title{
Scapteriscus didactylus (Orthoptera, Gryllotalpidae), predator of leatherback turtle eggs in French Guiana
}

\author{
Alexandra Maros, Alain Louveaux, Matthew H. Godfrey, Marc Girondot*
}

Laboratoire d'Ecologie, Systématique et Evolution (UPRESA 8079), Bâtiment 362 Université Paris Sud, Orsay 91405 cedex, France

\begin{abstract}
The present study describes the potential role of the insect Scapteriscus didactylus in egg mortality in nests of the leatherback sea turtle Dermochelys coriacea found in the Amana natural reserve in French Guiana. Out of the 3 mole cricket species (Scapteriscus didactylus [Latreille], $S$. borellii Giglio-Tos, Neocurtilla hexadactyla Perty) observed in the natural reserve, only S. didactylus was encountered on the sandy beaches where 4 species of marine turtles nest. Controlled experiments, in which $S$. didactylus individuals of various age classes and leatherbacks eggs were placed together, revealed that only the last instar nymphs of $S$. didactylus preyed on the eggs, making a characteristic round hole underneath the eggs in the sand. This same distinctive damage to eggs was seen in natural leatherback nests at Awala-Yalimapo beach in the Amana natural reserve. The predation affected on average $18 \%$ (range: 3.6 to $40.0 \%$ ) of all yolked eggs in the nests. Juvenile $S$. didactylus were present on the beach throughout the nesting season of leatherback turtles, while adult $S$. didactylus were observed when the nest density on the beach reached its seasonal maximum at the end of July.
\end{abstract}

KEY WORDS: Mole cricket $\cdot$ Predation $\cdot$ Insects $\cdot$ Dermochelys coriacea $\cdot$ Sea turtle $\cdot$ Leatherback

\section{INTRODUCTION}

Leatherback sea turtles Dermochelys coriacea are the most common of the 4 marine turtle species that lay eggs in French Guiana, the other 3 species being green Chelonia mydas, olive ridley Lepidochelys olivacea and hawksbill Eretmochelys imbricata turtles. The beaches of French Guiana receive almost $30 \%$ of the world's population of breeding leatherback females. On a worldwide scale, leatherbacks are classified as critically endangered by IUCN (Hilton-Taylor 2000). Large decreases in nest numbers have been observed at the main rookeries in Mexico and Malaysia (Chan \& Liew 1996, Sarti et al. 1996, Spotila et al. 1996, 2000). In Suriname and French Guiana, nest numbers have decreased from 60000 in 1988 and 1992 to 31000 in 2000 (Girondot et al. 2002).

Several hypotheses have been forwarded to explain the recent decline in French Guiana and Suriname, including migration to new beaches and increased nest destruction. Aerial surveys in Suriname (1997) and French Guiana (1998) suggested that there are no new major nesting sites (Chevalier et al. 1998). Destruction of eggs and adults by poachers and predators such as dogs is not great enough to explain a major decline (Chevalier et al. 1998). The hypothesis that the reduction is a natural fluctuation in population size due to density-dependent mechanisms has also been excluded as the sole factor (Girondot et al. 2002). Interaction of turtles with fisheries, particularly the Suriname driftnet fishing in the Maroni estuary, is likely to be a major source of adult mortality (Chevalier et al. 1998). Another of the many possible causes of the decline is that the nests laid in French Guiana have a low hatching success.

At Awala-Yalimapo beach in French Guiana, the hatching success of leatherback nests was only about $30 \%$ in 2000 (M. H. Godfrey unpubl.). Studies of hatching success on other beaches in the same region have suggested that several factors can increase egg mortality, including washover by extreme high tides (Whitmore \& Dutton 1985, Schouten et al. 1997, Hoekert et 
al. 1998) and bacterial and fungal attacks that increase during the nesting season (Girondot et al. 1990). Another potential factor reducing hatching success is egg predation. In Suriname, $40 \%$ of Dermochelys coriacea eggs and $20 \%$ of green turtle eggs were preyed on during incubation (Hoekert et al. 1998). On the same beach in Suriname, Schouten et al. (1997) stated that mole crickets ate $8 \%$ of all leatherback eggs. However, the criteria used to infer destruction of the eggs by mole crickets were not specified, and other predators could also have been responsible. Indeed, ghost crabs, ants, and larvae of the fly Megaselia scolaris were often observed in the clutches of sea turtles in Suriname (Whitmore \& Dutton 1985).

The ecology and biology of mole crickets on nesting beaches remain unknown. As a first step towards a better understanding of these insects in the beach ecosystem, we identified the species in the Amana natural reserve in French Guiana and determined whether they attacked the eggs of sea turtles. Eggs are abundant and provide a seasonal supply of food to many opportunist predators, therefore we also looked at the developmental cycle and distribution of mole crickets relative to the nesting cycle of leatherbacks in French Guiana. We hypothesized that mole cricket density would be related to availability of incubating sea turtle eggs.

\section{MATERIALS AND METHODS}

Study site. Mole crickets were collected from the end of May through July 2001, when the nesting season of

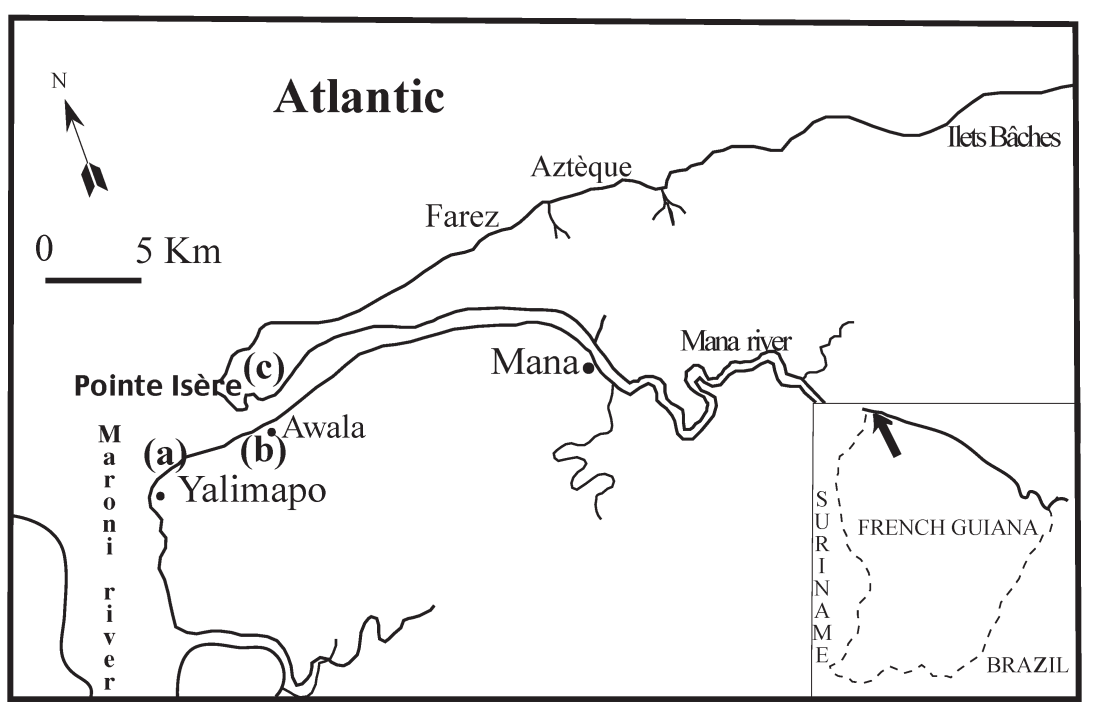

Fig. 1 Study site in French Guiana. Mole crickets Scapteriscus didactylus were collected at 3 different locations: (a) Awala-Yalimapo beach at the mouth of the Maroni and Mana rivers, (b) a marsh $1 \mathrm{~km}$ inland, and (c) a lagoon on Pointe Isère near the mouth of the Mana river marine turtles in French Guiana reaches its maximum. The work was conducted at 3 different sites in the natural reserve of Amana: (1) Awala-Yalimapo beach, which is $3.6 \mathrm{~km}$ long and located in the mouth of the Maroni and Mana rivers, (2) a marsh located $1 \mathrm{~km}$ inland from the beach, and (3) a lagoon on Pointe Isère near the mouth of the Mana river (Fig. 1a,b,c, respectively). All distances were measured using a Magellan Blazer 12 GPS (precision $\pm 15 \mathrm{~m}$ ).

Identification of mole crickets and developmental stages. Individuals were caught by hand in their burrows and preserved in $90 \%$ alcohol. Adults attracted to artificial lights at night were also collected and preserved. We used the species key of Nickle \& Castner (1984) for identification. Four developmental stages were categorized as follows: young with alar rudiments in downward position, 2 juvenile instars with alar rudiments reversed upward (penultimate and ultimate instars), and adults. In adults, males were recognized by the presence of a stridulatory file on the wings.

Mole crickets tunnel characteristics. Mole crickets abundance on Awala-Yalimapo beach was estimated using their burrows as an index of presence. Mole crickets construct tunnels beneath the surface and leave trails of pushed-up soil that look like miniature mole tunnels. The tunnels cannot be confused with those constructed by ghost crabs (Ocypoda spp.) that also inhabit the beaches of the Amana natural reserve. The length of each tunnel was measured by a method usually used to calculate root length (Böhm 1979). The sampling unit was a $1 \times 1 \mathrm{~m}$ squared grid with $5 \mathrm{~cm}$ mesh size, in which we counted the number of intersections between the lines of the grid and the tunnels inside. Tunnel length was estimated by the following equation: $L=(\pi A N) / 2 H$, where $L$ is the total length of the tunnel in a grid of area $A$, and $N$ is the number of intersections between the tunnel and grid lines of total length $H$ (Böhm 1979). Following Böhm (1979), an accurate estimate of lengths is achieved if the counted number of intersections is more than 50. Practical tests done by Newman (1966) and others indicate that there are only small differences in the precision between the data from the direct measurements and those obtained from the intersection method. These authors found that in no case was the standard deviation more than $\pm 10 \%$ of the true lengths. The size of the grid, $1 \mathrm{~m}^{2}$, was chosen to maintain high precision. Sampling points on the beach were located 
$300 \mathrm{~m}$ apart and repeated all along the $3.6 \mathrm{~km}$ of the beach. A total of 76 tunnels were measured along the whole beach on 3 separate occasions during June and July. We measured length using the method described above, and we measured the width of the tunnel with a centimeter rule.

Spatial distribution of mole crickets on the beach. A second sampling method was employed to obtain the spatial and temporal distribution of the mole cricket population on the beach. When the nesting season of leatherbacks reached its maximum in June and July, we counted all visible tunnels along the $3.6 \mathrm{~km}$ long beach. Data were grouped by $300 \mathrm{~m}( \pm 15 \mathrm{~m})$ wide sections of the beach. Wind and heavy rain can efface tunnels, so the timing of our sampling was dependent on weather conditions, and restricted to only 5 occasions during June and July.

Predation experiments. To test for mole cricket predation of the eggs of Dermochelys coriacea, we placed 2 freshly laid leatherback eggs ( $5 \mathrm{~cm}$ diameter), collected from natural nests, together with mole crickets in a $20 \mathrm{l}$ bucket filled with sand. The sand was collected from the nesting beach at nest depth. The bucket was kept covered to maintain moisture content, with periodic additions of water to maintain roughly 1 to $5 \%$ moisture content, similar to beach sand. For each experiment, we inspected the eggs every $3 \mathrm{~d}$ over a total of $9 \mathrm{~d}$ for signs of predation. The bucket was maintained indoors at $28 \pm 5^{\circ} \mathrm{C}$. The eggs were placed $20 \mathrm{~cm}$ deep in the sand, and the mole crickets were initially placed on top of the sand. We conducted 3 different experiments: the first with a pair of adult Neocurtilla hexadactyla collected at an inland site; the second with a pair of adult Scapteriscus borellii collected in a marsh; the third with 3 pairs of nymphs and 1 pair of juveniles of Scapteriscus didactylus that had been collected from the Awala-Yalimapo beach. The third experiment was repeated an additional time with a single leatherback egg.

Predation in natural leatherback nests. To check for predation in natural nests on Awala-Yalimapo beach, we inspected 10 leatherback nests after the emergence of the hatchlings, 4 in the 2001 and 6 in the 2002 nesting season. We exhumed all eggs and empty shells, and separated the contents into the following categories: hatched eggs, unhatched but yolked eggs, and yolkless eggs. Yolkless eggs are generally smaller than fertile eggs and contain almost exclusively albumin, although traces of yolk are sometimes also seen (Schulz 1975). Eggs with damage similar to those observed in the bucket experiments (Fig. 2) were attributed to mole crickets. Damage to eggs from ghost crabs (Ocypoda spp.) and ants (unidentified species) in Awala-Yalimapo have been described previously by Viseux (2001) in experimental conditions. Signs of pre-

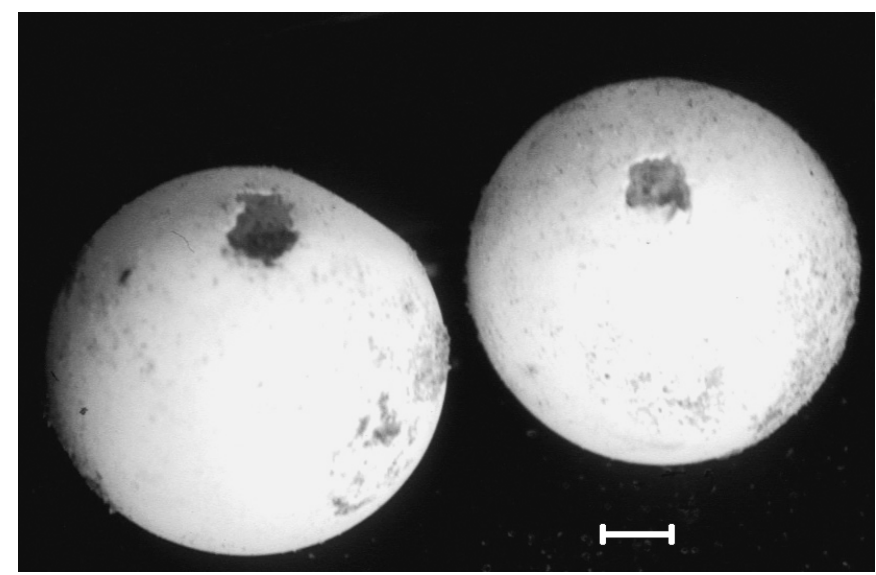

Fig. 2. Characteristic damage caused by mole crickets Scapteriscus didactylus on leatherback turtle Dermochelys coriacea eggs. Scale bar $=1 \mathrm{~cm}$

dation by crabs and ants are easily distinguished from those of mole crickets even at the end of incubation of the turtle eggs.

\section{RESULTS}

\section{Mole cricket species}

Eighty-three mole crickets were collected. Twenty adults of Neocurtilla hexadactyla were trapped under the night lighting of the Amana reserve building, which is located $50 \mathrm{~m}$ behind the beach and separated from the ocean by forest vegetation. Five adults and 10 nymphs of Scapteriscus borellii (4-dot form) were caught by hand in their tunnels at the marsh and the lagoon sites. Eight adults and 40 juveniles of $S$. didactylus were captured in the same manner on AwalaYalimapo beach. S. didactylus was the only mole cricket species observed on the beach. We observed that $S$. didactylus nymphs burrowed into the sand surface at night and during high tide. The tunnels were found mostly along the high tide line.

\section{Tunneling activity of mole crickets}

The demographic structure of the mole cricket population can be estimated from tunneling activity, as this activity is related to the age and size of the individuals occupying the tunnels. We observed a non-linear trend between width and length of the tunnels (Fig. 3). In June, the mean width was $1.48 \mathrm{~cm}$ and increased to $2.30 \mathrm{~cm}$ by mid-July. Smaller tunnels were present both months, but larger tunnels were present only in 


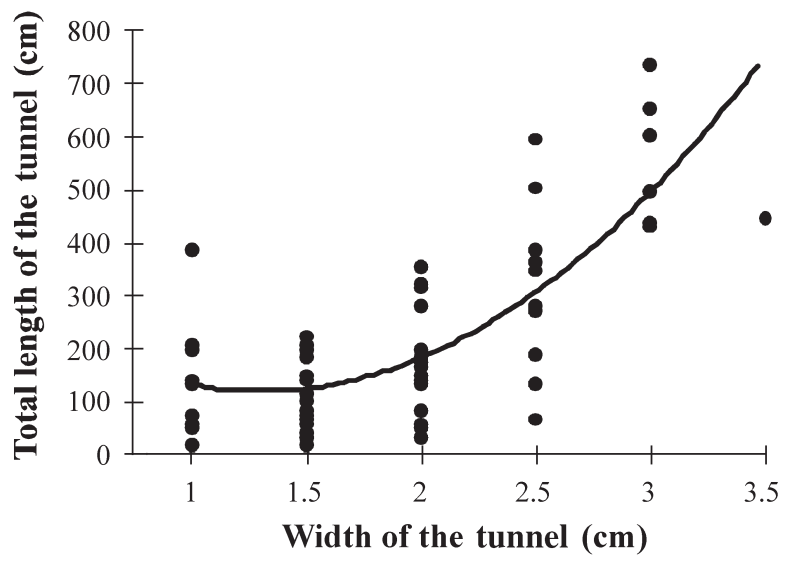

Fig. 3. Scapteriscus didactylus. Relationship between length and width of a tunnel, fitted by a second degree polynomial function $y=\mathrm{P} 1 x_{1}{ }^{2}+\mathrm{P} 2 x_{1}+\mathrm{P} 3\left(\mathrm{r}^{2}=0.58\right) . \mathrm{P} 1=131.4 \pm 28.4$, $\mathrm{P} 2=346.2 \pm 115.5$ and $\mathrm{P} 3=342.6 \pm 110.1$

July, suggesting an age shift towards older individuals in the population (Fig. 4). This was confirmed by increased capture of larger individuals in July (A. Maros pers. obs.). There was also a strong relation $\left(\mathrm{r}^{2}=0.81\right)$ between size body and width of the tunnels of adults and juveniles reared in the 201 buckets (Fig. 5). The persistence of small tunnels from May to the end of July indicated that some hatching occurs all the time. We observed no adults attracted to nighttime lighting or inside tunnels during June and July. The few adults caught in May belonged to the previous generation. Observations of tunnels mainly of small sizes at the beginning of June confirmed that reproduction of Scapteriscus didactylus had occurred a few weeks before. Young of the 2 last instars were caught by the end of July, consistent with the arrival of adults at the end of July and August.

\section{Distribution of the tunnels on the beach}

Sampling of tunnels at $300 \mathrm{~m}$ intervals along the beach began on 1 June and ended on 5 July. At each sampling occasion, lower concentrations of tunnels were observed in 2 locations that were also sites of entry for tourists and the local population on the beach (Fig. 6). We found also fewer tunnels at each extremity of the beach, where the beach is much narrower and washed more often by sea tides. We did not find any relationships, either positive or negative, between concentrations of turtles nests and mole crickets (Fig. 6). Over the course of the nesting season, the number of tunnels increased from the end of May to the beginning of July, particularly in the area with heavy human beach traffic (Fig. 6). At the same time, the nesting sea- son of the leatherback turtles was coming to an end and large concentrations of eggs incubating in the sand were available for mole crickets (Fig. 7). As the nesting season of green turtles stretches between January and May (Fig. 7), there are at least some turtle eggs in the sand nearly all months during the year.

\section{Experimental egg predation by mole crickets}

Predation on eggs in experimental conditions was observed only by Scapteriscus didactylus nymphs and 2 juveniles with unreversed alar rudiments. Neither Neocurtilla hexadactyla nor $S$. borellii in their adult
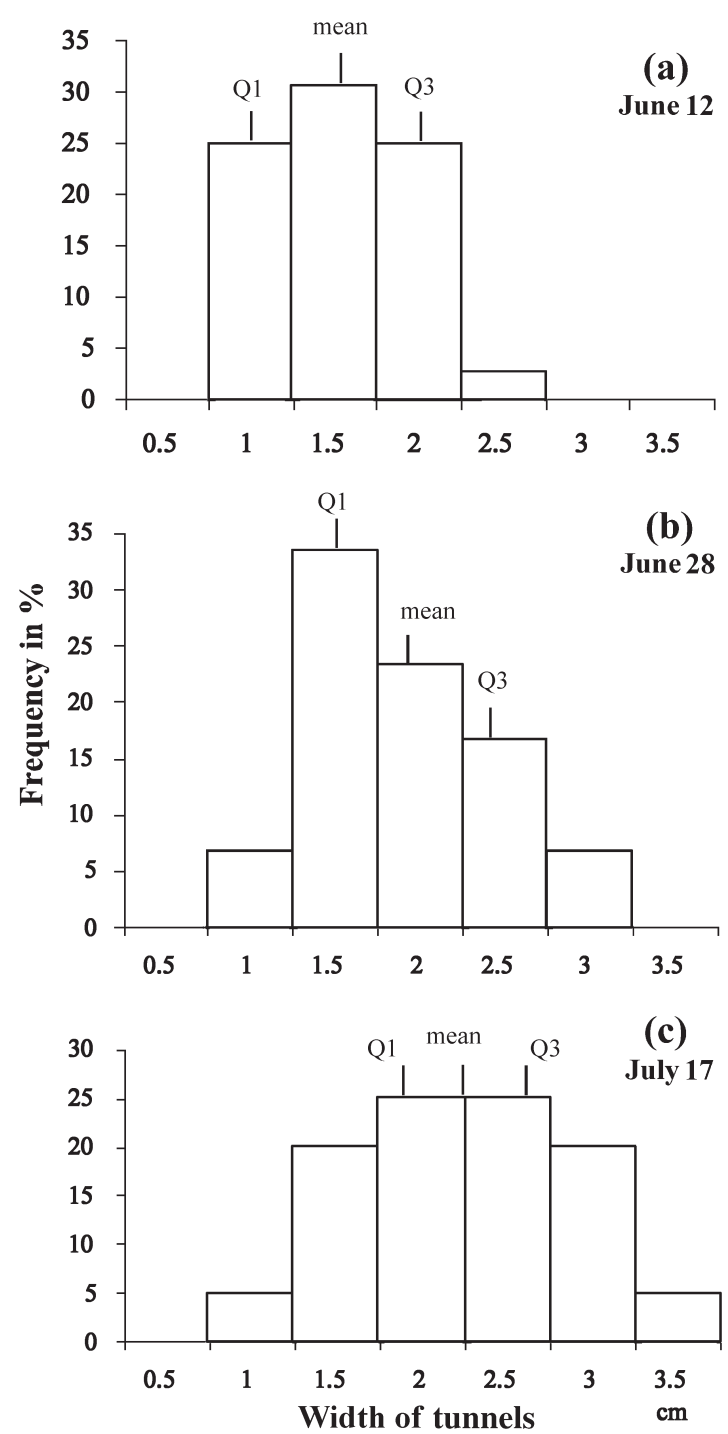

Fig. 4. Scapteriscus didactylus. Histogram of mean tunnel width on Yalimapo beach during the development of the juveniles. Q1-Q3 interval encloses $50 \%$ of the data. Sampling dates: (a) June 12, (b) June 28, (c) July 17 
forms were observed attacking the eggs in experimental conditions. Juveniles of these 2 species were not tested. $N$. hexadactyla and $S$. borellii have never been observed on the beach, so they were not expected to cause predation. As early as the third day, $S$. didactylus had bored a hole in the shell of 1 egg, on the inner face of the egg. Half of the contents of both eggs had been eaten $3 \mathrm{~d}$ later. The holes made by the mole crickets were irregular: $15 \mathrm{~mm}$ length and $9 \mathrm{~mm}$ width for the first egg and $12 \mathrm{~mm}$ length and $9 \mathrm{~mm}$ width for the second (Fig. 2). This experiment was repeated with only $1 \mathrm{egg}$, with the same results (hole of $9.3 \mathrm{~mm}$ length and $6.5 \mathrm{~mm}$ width). We observed that the small juveniles with unreversed alar rudiments remained underneath the surface of the sand and were never found near the eggs, while the 2 last instars were found at the bottom of the bucket in the vicinity of the eggs.

\section{Natural rate of egg predation}

When natural nests on the beach were examined a few days after their emergence, we found damage to unhatched eggs similar to those observed in experimental conditions (Fig. 2). Some yolked eggs were broken, rotten or unhatched without any evident cause of mortality. No signs of typical crab or ant damage were observed. Mole crickets attacked both yolked and yolkless eggs. The mean percentage of yolked eggs preyed on by mole crickets was $18.1 \% \pm 4.5$ SEM (range: 3.6 to $40.0 \%, \mathrm{n}=10$ nests) (Table 1). Mole cricket predation was more concentrated on yolked eggs than on yolkless eggs $\left(\chi^{2}=6.8, \mathrm{df}=1 ; \mathrm{p}=0.01\right)$.

\section{DISCUSSION}

Whitmore \& Dutton (1985) observed that $6.3 \%$ of eggs were ruptured in relocated leatherback clutches in Suriname. They indicate ghost crabs, maggots, locust larvae and ants as potential predators of turtle eggs. However, we did not observe predation by any invertebrates other than mole crickets in our study nests. Crabs cause a very different and distinctive slit of several $\mathrm{cm}$ in the eggshell, and ants make a small hole a few $\mathrm{mm}$ in diameter (Viseux 2001). Perhaps a larger sample size over a longer time period may reveal other instances of predation. Locust larvae described in nests of marine turtles by Whitmore \& Dutton (1985) were probably misidentified juveniles of mole crickets.

We found that mortality of yolked eggs in nests laid at Awala-Yalimapo was as high as $70 \%$, while mole crickets on average preyed on only $18 \%$ of all yolked eggs in the nests. Others factors affecting emergence

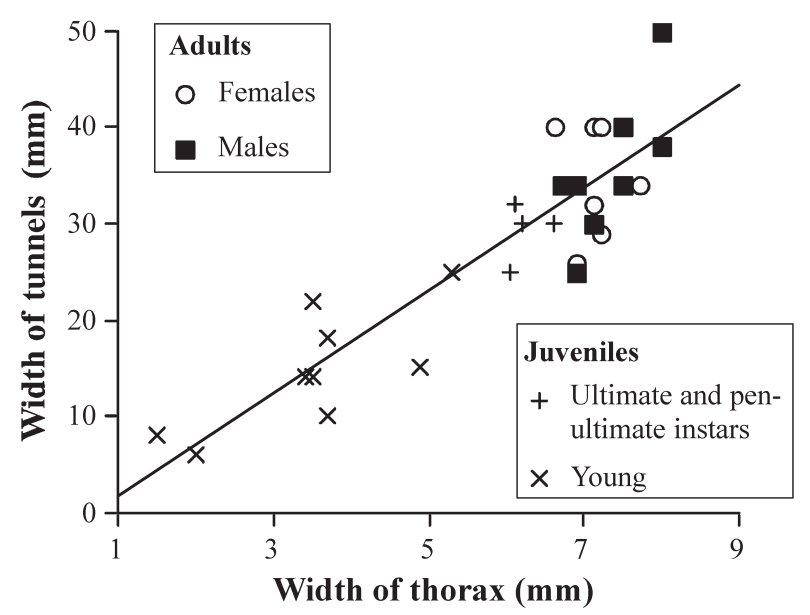

Fig. 5. Scapteriscus didactylus. Relationship between mole cricket thorax width and tunnel width at the surface of the sand $\left(y=-3.5+5.1 \times x_{i} r^{2}=0.81\right)$

success of sea turtle nests in Awala-Yalimapo include: bacteria and fungus (Girondot et al. 1990), other nesting sea turtles (Girondot et al. 2002), predation by birds (Fretey \& Lescure 1981), and predation by dogs (Viseux 2001). On other nesting beaches, where egg mortality in leatherback nests is lower, the relative impact of egg predation by mole crickets, should they be present on the nesting beach, could be higher. It should be stressed that current mole cricket distribution is not fully known. Scapteriscus didactylus has been recently reported in Australia (Cribb 1998 ${ }^{1}$ ). Interestingly, we found that some mole crickets had also attacked some yolkless eggs (Table 1). The addition of yolkless eggs in leatherback nests may in this case act as a predator satiation mechanism, as mole crickets that encounter and eat yolkless eggs may attack fewer yolked eggs. It would be interesting to compare predation rates between nests of green turtles, which typically do not have yolkless eggs, and nests of leatherbacks, although crabs have been reported to preferentially attack leatherback eggs more often than green turtle eggs (Whitmore \& Dutton 1985).

Sampling juvenile crickets by hand is a laborious technique; however, the width of the tunnels is more easily measured and is an index of the size and age of individuals that constructed them. We found that tunnels in dry sand could be easily effaced or destroyed by the wind. Thus, tunnels had to be measured soon after they were constructed, which corresponds to high tide

\footnotetext{
${ }^{1}$ Cribb J (1998) The cricket that might eat cricket: Changa mole cricket. CSIRO Australia-Media release 98/239, available at www.csiro.au/news/mediarel/mr1998/mr98239.html
} 


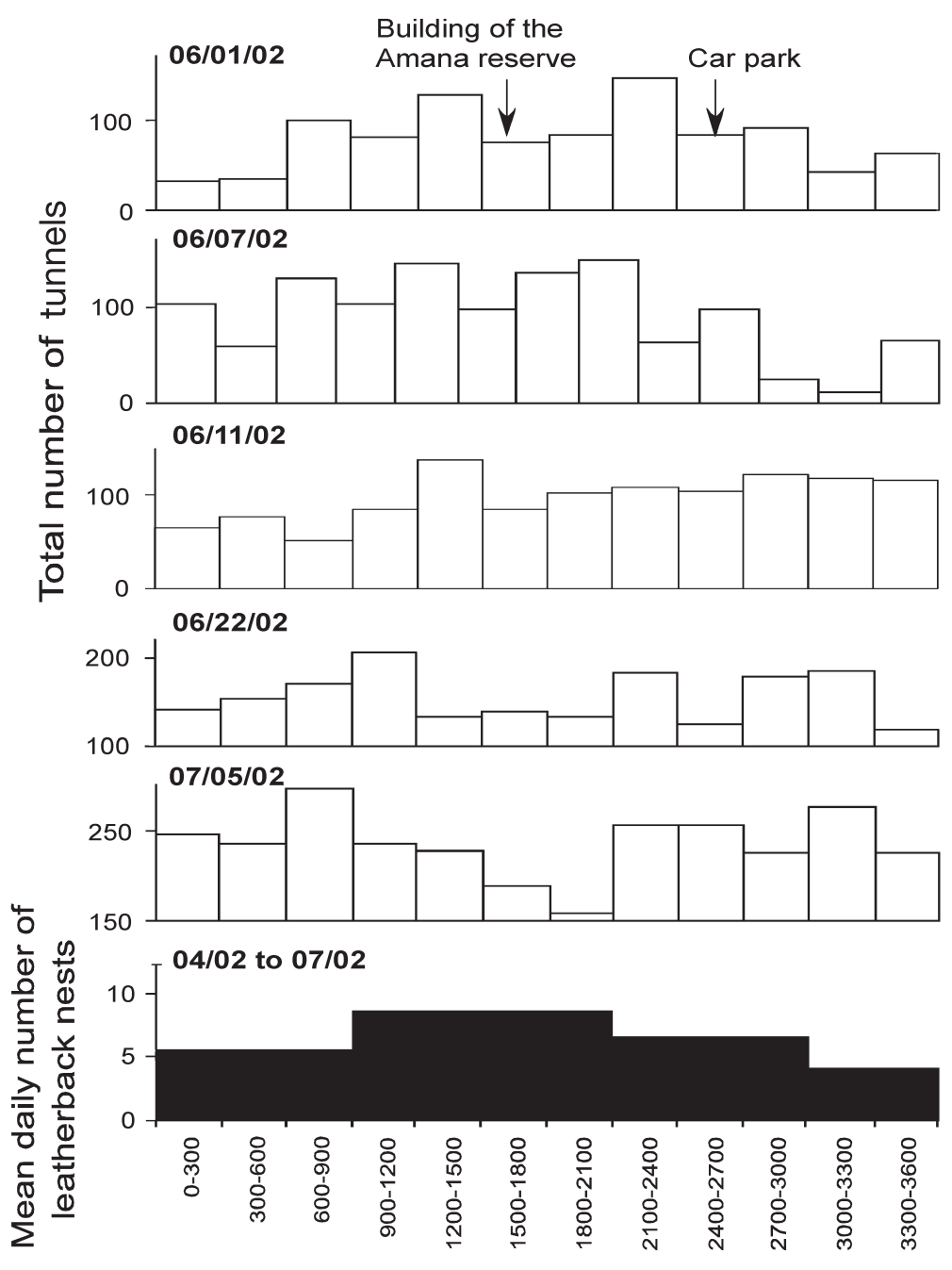

Distance along the beach in meters

Fig. 6. Scapteriscus didactylus. Distribution of the tunnels along the AwalaYalimapo beach on 5 different sampling dates during June and July 2001. All tunnels were counted along the beach and grouped by $300 \mathrm{~m}$ wide sections of the beach. Mean distribution of leatherback turtles' (Dermochelys coriacea) nests along the beach during the same period is also shown on Awala-Yalimapo beach. Counting tunnels also provides information on density and distribution of beach populations. Improving sampling methods will help to increase our knowledge of the life cycle of Scapteriscus didactylus.

The 3 mole crickets species collected at the Amana Natural Reserve in French Guiana have been previously reported to occur in contrasting habitats. Neocurtilla hexadactyla prefers heavy clay soils, Scapteriscus didactylus abounds in sand and $S$. borellii occurs also in sandy soils but more particularly near fresh water (Fowler \& De Vasconcelos 1989). The diet of $N$. hexadactyla has not yet been identified. S. borellii was described as carnivorous (Matheny 1981, Castner \& Fowler 1984). Analysis of gut contents of $S$. didactylus collected on beaches in the Dominican Republic showed that they were carnivorous (Franck et al. 1987), although this species had been previously described as being mainly herbivorous, living inland and causing damages to crops (Castner \& Fowler 1984, Fowler et al. 1985). In the current study, $S$. didactylus ate turtle eggs in experimental and natural conditions, suggesting a carnivorous diet. It could be that $S$. didactylus is omnivorous and opportunistically eats plants or animals that are abundant. In the studies suggesting a herbivorous diet, the majority of individuals were collected on a golf-course where there were plenty of available food plants (Castner \& Fowler 1984, Fowler et al. 1985). Thus, in French Guiana $S$. didactylus may opportunistically prey on turtle eggs when

Month of the year

\begin{tabular}{|l|l|l|l|l|l|l|l|l|l|l|l|}
\hline J & F & M & A & M & J & J & A & S & O & N & D \\
Species
\end{tabular}
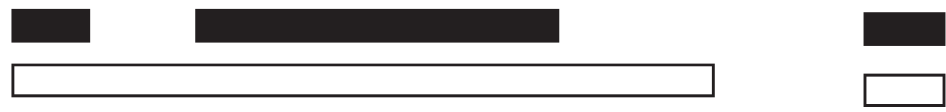

Leatherback turtles

Green turtles

Olive ridley turtles
Fig. 7. The seasonal occurrence of nesting turtles and eggs in French Guiana: breeding females of leatherback Dermochelys coriacea (Girondot \& Fretey 1996), green Chelonia mydas (Schulz 1975) and olive ridley Lepidochelys olivacea (Fretey 1989) turtles. Black bars: adults; white bars: eggs 
Table 1. Dermochelys coriacea. Contents of leatherback turtle nests (1-10) exhumed after completion of egg incubation on Awala-Yalimapo beach, French Guiana

\begin{tabular}{|c|c|c|c|c|c|c|c|c|c|c|c|c|}
\hline & \multicolumn{4}{|c|}{ — Year 2001} & \multicolumn{4}{|c|}{ - Year 2002} & \multirow[b]{2}{*}{9} & \multirow[b]{2}{*}{10} & \multirow[t]{2}{*}{ Mean } & \multirow[t]{2}{*}{ SE } \\
\hline & 1 & 2 & 3 & 4 & 5 & 6 & 7 & 8 & & & & \\
\hline Total clutch size when laid & 65 & 50 & 82 & 96 & 86 & 52 & 92 & 90 & 110 & 118 & 84.1 & 6.8 \\
\hline Yolkless eggs & 37 & 3 & 19 & 29 & 13 & 12 & 21 & 50 & 23 & 21 & 22.8 & 4.0 \\
\hline Yolked eggs & 28 & 47 & 63 & 67 & 73 & 40 & 71 & 40 & 87 & 97 & 61.3 & 6.6 \\
\hline Number of hatched eggs & 7 & 18 & 24 & 21 & 18 & 1 & 24 & 35 & 32 & 40 & 22 & 3.6 \\
\hline Hatching success $(\%)$ & 25.0 & 38.3 & 38.1 & 31.3 & 24.7 & 2.5 & 33.8 & 87.5 & 36.8 & 41.2 & 35.9 & 7.1 \\
\hline \multicolumn{13}{|l|}{ Predation by mole crickets } \\
\hline on yolked eggs & 1 & 7 & 16 & 25 & 5 & 16 & 13 & 1 & 9 & 20 & 11.3 & 2.4 \\
\hline$\%$ of predation & 3.6 & 14.9 & 25.4 & 37.3 & 6.8 & 40.0 & 18.3 & 2.5 & 10.3 & 20.6 & 18.1 & 4.5 \\
\hline on yolkless eggs & 1 & 0 & 4 & 10 & 0 & 0 & 1 & 1 & 0 & 7 & 2.4 & 1.0 \\
\hline Other causes of mortality & 20 & 22 & 23 & 21 & 50 & 23 & 34 & 4 & 46 & 37 & 28 & 4.1 \\
\hline
\end{tabular}

turtle nests are abundantly available on the beach for several months of a year.

Although our studies were restricted to $4 \mathrm{mo}$, our results suggest that the presence of juvenile and adult Scapteriscus didactylus on the beach is related to the nesting activity of sea turtles. Some green turtle and leatherback nests are present year-round on AwalaYalimapo beach, although mostly in low quantities outside of the main nesting periods. We hypothesize that juvenile $S$. didactylus of all instars may be present throughout the year, while adults would be present around the time of greatest concentrations of turtle nests (April for green turtles, June/July for leatherbacks), in order to take advantage of the increased availability of eggs as food (Fig. 7). Last instar and adults seem the most likely to attack eggs.

In the Amazon basin, Scapteriscus didactylus may reproduce throughout the year, and with large adult population increases in short time periods, and they can rapidly colonize new nesting sites (Fowler et al. 1989). A test of the idea that an increased presence of adults in local populations of $S$. didactylus in French Guiana is tied to turtle egg concentrations would be to look at other beaches where other sea turtles nest. For instance, the olive ridley turtle has a nesting peak in August on more isolated beaches (Fretey 1989), thus there may be a peak in adult mole crickets in August and September on these isolated beaches (Fig. 7). Studies are underway to further investigate the annual cycle of $S$. didactylus populations on nesting beaches, and to measure the interaction between $S$. didactylus and sea turtle eggs. Greater knowledge of egg predators is essential for refinement of conservation policies for leatherbacks and other species of sea turtle in French Guiana and elsewhere.

Acknowledgements. We thank the conservateur and the guards of the Amana Natural Reserve for their assistance, the members of the Kulalasi association, and the other temporary workers for aiding in the collection of the mole crickets. Sea turtle conservation research in French Guiana is financed by DIREN-Guyane. We are indebted to the referees for their comments which improved the quality of the manuscript.

\section{LITERATURE CITED}

Böhm W (1979) Methods of studying root systems. SpringerVerlag, Berlin

Castner JL, Fowler HG (1984) Gut content analyses of Puerto Rican mole crickets (Orthoptera: Gryllotalpidae: Scapteriscus). Fla Entomol 67:479-481

Chan EH, Liew HC (1996) Decline of the leatherback population in Terengganu, Malaysia, 1956-1995. Chelon Conserv Biol 2:196-203

Chevalier J, Cazelles B, Girondot M (1998) Apports scientifiques à la stratégie de conservation des tortues luths en Guyane française. J Agric Tradit Bot Appl Rev Ethnobiol XL:485-507

Fowler HG, De Vasconcelos HL (1989) Preliminary data on life cycles of some mole crickets (Orthoptera, Gryllotalpidae) of the Amazon basin. Rev Bras Entomol 33:139-141

Fowler HG, Vieira De Camargo MT, Crestana L (1985) Feedings habits of Brazilian mole crickets (Orthoptera: Gryllotalpidae: Scapteriscus spp. and Neocurtilla sp.). J Econ Entomol 78:1076-1078

Franck JH, Woodruff RE, Nuñez CA (1987) Scapteriscus didactylus (Orthoptera: Gryllotalpidae) in the Dominican Republic. Fla Entomol 70:478-483

Fretey J (1989) Reproduction de la Tortue olivâtre (Lepidochelys olivacea) en Guyane française pendant la saison 1987. Nat Guyan 1:8-13

Fretey J, Lescure J (1981) Prédation des tortues marines par les oiseaux en Guyane française. Oiseau 51:139-145

Girondot M, Fretey J (1996) Leatherback turtles, Dermochelys coriacea, nesting in French Guiana, 1978-1995. Chelon Conserv Biol 2:204-208

Girondot M, Fretey J, Prouteau I, Lescure J (1990) Hatchling success for Dermochelys coriacea in a French Guiana hatchery. In: Ridchardson TH, Ridchardson JI, Donnelly M (eds) Proc 10th Annu Workshop Sea Turtle Biology and Conservation, 229-232, NOAA Technical Memorandum NMFS-SEFC-278, Miami

Girondot M, Tucker AD, Rivalan P, Godfrey MH, Chevalier J 
(2002) Density-dependent nest destruction and population fluctuations of Guianan leatherback turtles. Anim Conserv 5:75-84

Hilton-Taylor C (2000) 2000 IUCN red list of threatened species. IUCN, Gand

Hoekert WEJ, Van Tienen LHG, Van Nugteren P, Dench S (1998) The sea turtles of Suriname 1997 - project: comparing relocated nests to undisturbed nests. In: Abreu AB, Marquez R, Sarti L (eds) Proc 18th Int Sea Turtle Symp. US Dept. of Commerce, NOAA Technical Memorandum NMFS-SEFSC-436, Miami, p 192-194

Matheny EL Jr (1981) Contrasting feedings habits of pest mole cricket species. J Econ Entomol 74:444-445

Newmann EI (1966) A method of estimating the total length of root in a sample. J Appl Ecol 3:139-145

Nickle DA, Castner JL (1984) Introduced species of mole crickets in the United States, Puerto Rico, and the Virgin Islands (Orthoptera: Gryllotalpidae). Ann Entomol Soc Am 77:450-465

Sarti ML, Eckert SA, Garcia NT, Barragan AR (1996) Decline of the world's largest nesting assemblage of leatherback turtles. Mar Turtle Newsl 74:2-5

Editorial responsibility: Otto Kinne (Editor), Oldendorf/Luhe, Germany
Schouten AD, Weijerman M, Van Tienen LHG, Hoekert WEJ (1997) Relocations of sea turtle nests of Lepidochelys olivacea, Dermochelys coriacea and Chelonia mydas in the Galibi nature reserve, Suriname. Stud Nat Hist Caribb Region 73:63-69

Schulz JP (1975) Sea turtles nesting in Surinam. Zool Verh 143:1-143

Spotila JR, Dunham AE, Leslie AJ, Steyermark AC, Plotkin PT, Paladino FV (1996) Worldwide population decline of Dermochelys coriacea: are leatherback turtles going extinct? Chelon Conserv Biol 2:209-222

Spotila JR, Reina RD, Steyermark AC, Plotkin PT, Paladino FV (2000) Pacific leatherback turtles face extinction. Nature 405:529-530

Viseux B (2001) Etude, à l'aide d'un SIG, de la prédation des œufs et juvéniles de tortues marines par les chiens et urubus en Guyane française: caractérisation de la prédation des œufs de Dermochelys coriacea par Ocypoda quadrata. MSc thesis, Université de Corse Pascal Paoli

Whitmore CP, Dutton PH (1985) Infertility, embryonic mortality and nest-site selection in leatherback and green sea turtles in Suriname. Biol Conserv 34:251-272

Submitted: February 15, 2002; Accepted: August 8, 2002 Proofs received from author(s): February 17, 2003 